\title{
Mapping Quantitative Trait Loci for Left-Sided Displacement of the Abomasum in German Holstein Dairy Cows
}

\author{
S. Mömke, ${ }^{*}$ H. Scholz, † K. Doll, $\ddagger$ J. Rehage, $†$ and O. Dist| ${ }^{\star 1}$ \\ *Institute for Animal Breeding and Genetics, and \\ †Clinic for Cattle, University for Veterinary Medicine Hannover, 30559 Hannover, Germany \\ ¥Clinic for Ruminants, Faculty for Veterinary Medicine, Justus-Liebig-University 35392 Giessen, Germany
}

\section{ABSTRACT}

A whole-genome scan using an affected paternal half-sib design was utilized to detect quantitative trait loci (QTL) for left-sided displaced abomasum (LDA) in German Holsteins. A total of 360 animals from 14 paternal half-sib families were genotyped, for a total of 306 polymorphic microsatellites. For a whole-genome scan, 221 markers were equally distributed over all 29 bovine autosomes, with an average distance of $13.7 \mathrm{cM}$. For fine-mapping, a total of 85 additional microsatellites were used. We identified genome-wide significant QTL on Bos taurus autosome (BTA) 1 (54.6 to $58.3 \mathrm{cM}$ ) and on BTA3 $(5.9 \mathrm{cM})$. Furthermore, 3 chromosomewide significant QTL were located on bovine chromosomes 21, 23, and 24. In addition, we found 11 QTL that cosegregated in grandsire families but that were not significant in the across-family analysis. These QTL were located on BTA5, 6, 10, 12, 15, 16, 17, 19, 23, and 26. This study is the first report on QTL for LDA and is a first step toward identifying single nucleotide polymorphisms for LDA-QTL.

Key words: quantitative trait locus, displaced abomasum, German Holstein cattle

\section{INTRODUCTION}

Health problems in dairy cattle affect their well-being and cause considerable economic losses for farmers. Displacement of the abomasum (DA) is an economically important and commonly observed disease in Holstein dairy cows. The abomasum can be displaced to the left or right. In 85 to $95 \%$ of all cases, a left-sided displaced abomasum (LDA) is observed (Constable et al., 1992). Genetic correlation between these 2 forms was estimated at $r_{g}=0.65$ (Ricken et al., 2004). Displaced abomasum is mainly seen in dairy cows of the breeds Ayrshire (Constable et al., 1992), Brown Swiss

Received April 10, 2008.

Accepted June 30, 2008.

${ }^{1}$ Corresponding author: ottmar.distl@tiho-hannover.de
(Constable et al., 1992), German Holstein (GH; Wolf et al., 2001a,b; Hamann et al., 2004; Ricken et al., 2004), Guernsey (Constable et al., 1992), Holstein-Friesian (Martin et al., 1978), and Jersey (Jubb et al., 1991). Prevalence of LDA was reported to be between 1.2 and $2.6 \%$ in GH (Wolf et al., 2001a; Hamann et al., 2004), and as high as 5.5\% in US Holsteins (Detilleux et al., 1997). Left-sided DA usually takes place around parturition and most often within the first 4 to 8 wk after a cow gives birth. The condition must usually be treated by veterinary surgery, which fixes the abomasum to the abdominal wall in its correct position. Significantly reduced milk, milk fat, and milk protein yields, as well as conception problems increase the culling risk for cows that have recovered from LDA after veterinary treatment (Geishauser et al., 1998; Wolf et al., 2001a; Hamann et al., 2004). On average, $47.7 \%$ of all cows affected by LDA were culled in the course of the first year after surgery (Wolf et al., 2001a; Ricken et al., 2005). In addition, the amount of milk in the first 60 $\mathrm{d}$ of lactation in LDA-affected cattle is reduced by 557 kg compared with healthy cows (Detilleux et al., 1997). The etiology of LDA seems to be multifactorial. Various environmental effects, such as twin births (Rohrbach et al., 1999; Wolf et al., 2001a), housing system (Wolf et al., 2001a), and feeding factors (concentrate feed with insufficient crude fiber; Grymer et al., 1982) were found to be significantly related to the prevalence of LDA. Heritabilities were estimated mostly between $h^{2}=0.2$ to 0.3 for DA in general (Wolf et al., 2001a,b; Hamann et al., 2004; Ricken et al., 2004) and up to $\mathrm{h}^{2}=0.53$ for LDA (Hamann et al., 2004). Ricken et al. (2004) found moderate to high positive genetic correlations between LDA and milk fat yield, milk protein yield, and milk yield, whereas fat and protein content were negatively correlated with LDA. It is therefore likely that some milk performance QTL for LDA and milk yield traits may overlap.

Displaced abomasum is often preceded by a decreased motility of the abomasum and is associated with malfunctions at the level of the intrinsic nervous system, combined with impaired cholinergic muscle responses 

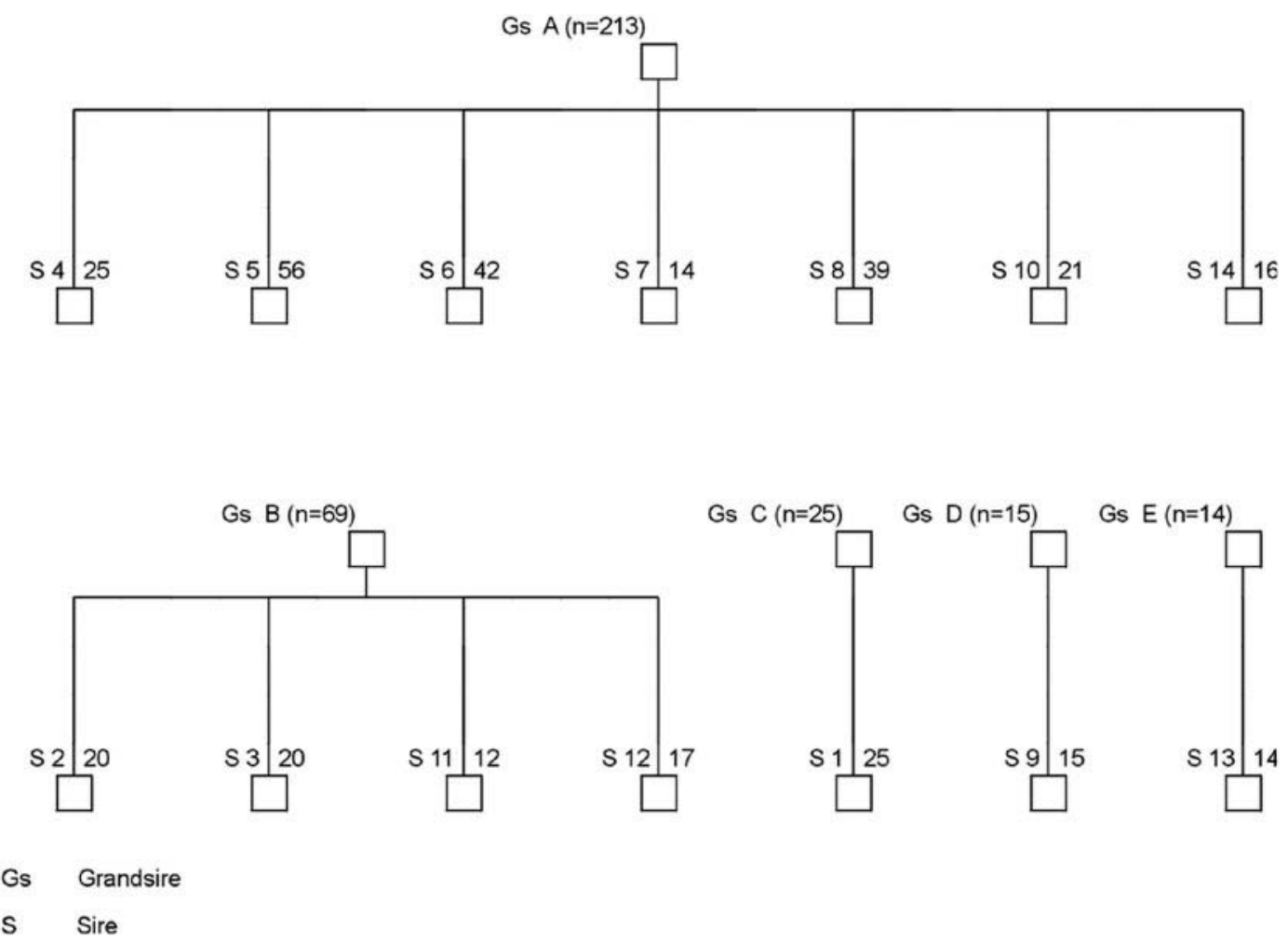

Figure 1. Family sizes and relationships among the sires of the genotyped cows affected by left-sided displaced abomasum. Seven sire families were descended from grandsire A, 4 from grandsire B, and 3 from grandsires unrelated to the others. The number of granddaughters per grandsire is shown in parentheses beside the designation of the grandsire. The family number is on the left side of each sire symbol, and the number of cows contained in each sire family is on the right side of each sire symbol.

(Geishauser et al., 1998). Furthermore, LDA-affected cattle showed a greater activity of nitric oxide synthase. The neurotransmitter substance $\mathrm{P}$, which stimulates gastric motility, and the vasoactive intestinal polypeptide, which inhibits gastric motility, may also play a role in the development of LDA (Sickinger, 2007). Because the abomasal atony in cows with DA depends on the persistence of high serum concentrations of insulin, insulin concentrations and myoelectrical activity of the abomasum are correlated (Pravettoni et al., 2004).

The objective of this study was to identify QTL for LDA in GH cows. For this purpose, a genome-wide scan using 306 microsatellite markers and 360 animals from 14 paternal half-sib families was performed to detect regions in the bovine genome significantly linked to LDA.

\section{MATERIALS AND METHODS}

\section{Sampling and Pedigree Structure}

For this study, samples from 352 cows and 8 sires belonging to 14 half-sib families were analyzed. These 14 half-sib families comprised 328 LDA affected cows and 24 unaffected control cows. Thus, LDA was scored as a dichotomous trait. We used blood samples from $352 \mathrm{GH}$ cows and semen samples from $8 \mathrm{GH}$ sires used in AI. From the total of 3,560 blood samples from LDA-affected cows, we chose 328 animals. These cows were positively affected by LDA, because they had been examined and submitted to LDA surgery at the Clinic for Cattle, University for Veterinary Medicine Hannover and at the Clinic for Ruminants, Justus-LiebigUniversity for Veterinary Medicine Giessen. Furthermore, we included 24 cows that had completed more than 7 lactations and that were never affected by LDA. We used these control cows and all LDA-affected cows to confirm heterozygosity of the QTL-linked markers of the sires. In this way, we were able to ensure that the QTL were supported by half-sib families whose sires were heterozygous for the QTL-linked markers. Falsely heterozygous genotypes could be excluded for the sires because we used a large number of markers in QTL intervals and controlled the genotypes of sires by determining the alleles identical by descent (IBD) in large progeny groups per sire and in unaffected progeny. Sires homozygous for QTL-linked markers are uninformative for linkage, and thus do not contribute to linkage test statistics. The paternal half-sib families consisted of 12 to 58 siblings of progeny-tested AI sires. 
Table 1. Quantitative trait loci for left-sided displacement of the abomasum analyzed across 14 paternal half-sib families in German Holstein cattle $^{1}$

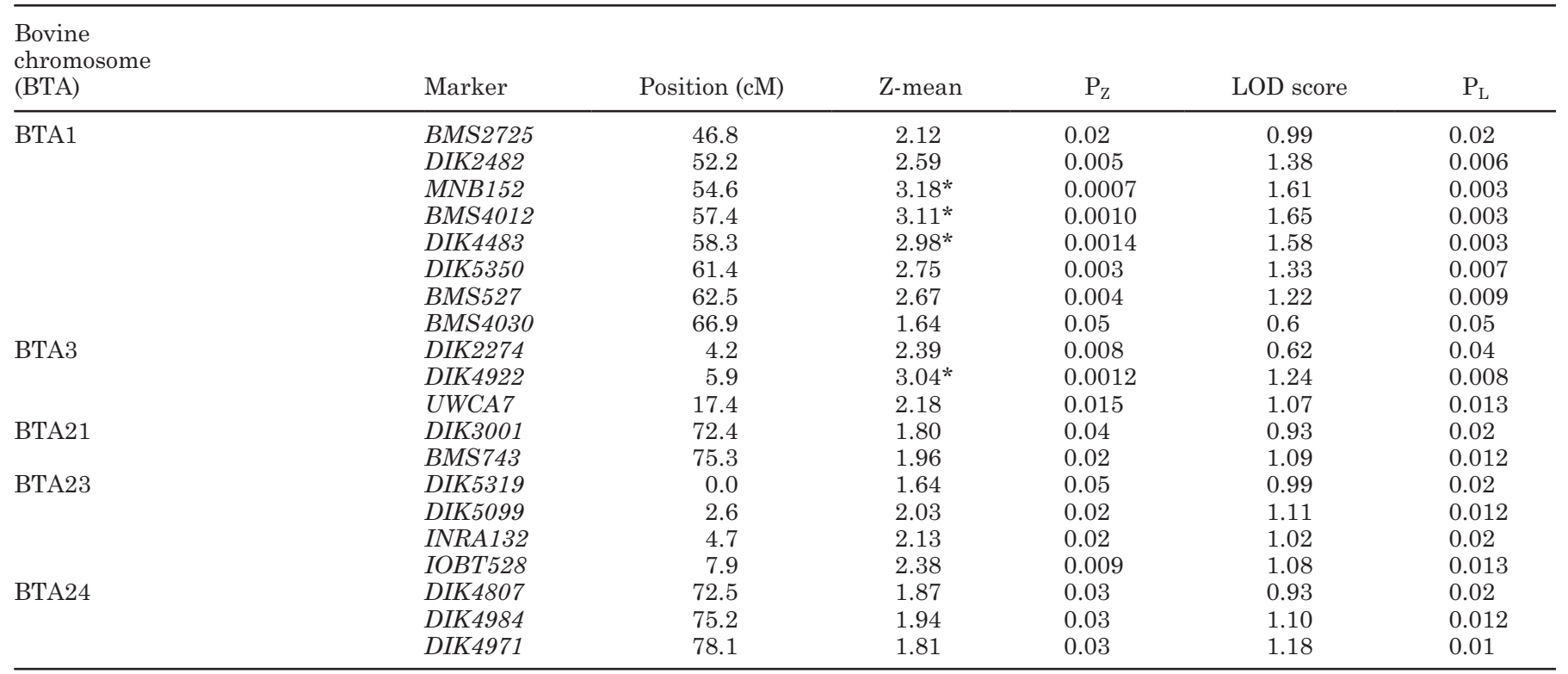

${ }^{1}$ Only markers with significant Z-means and LOD (logarithm of the odds) scores are shown with their position on the respective bovine chromosome (BTA) and their chromosome-wide $\left(\mathrm{P}_{\mathrm{Z}}, \mathrm{P}_{\mathrm{L}}\right)$ and genome-wide error probabilities.

${ }^{*}$ Genome-wide error probability $(P<0.05)$.

The average family size was 25.1 cows. The pedigrees of 7 sires could be traced back to a common grandsire. A further common grandsire, unrelated to the first one, was ascertained for 4 sires. The remaining 3 families were not closely related to the other families (Figure 1). Semen samples of 8 sires were provided by AI stations. Genomic DNA from EDTA blood samples was extracted by using the NucleoSpin kit (Macherey-Nagel, Düren, Germany). For semen samples, the Nucleon BACC2kit for blood and cell cultures (Amersham Biosciences, Freiburg, Germany) was used.

\section{Microsatellite Markers}

We selected 221 highly polymorphic microsatellite markers to achieve a uniform coverage of all bovine autosomes, comprising $3,022.5 \mathrm{cM}$ with an average pairwise distance of $13.7 \mathrm{cM}$ (Ihara et al., 2004). We used 7.6 markers per chromosome, on average. An additional 85 microsatellite markers were included for fine-mapping of QTL on 14 chromosomes showing significant linkage with LDA. The average distance among markers on these chromosomes was $7.9 \mathrm{cM}$, and on average, we analyzed 13.7 markers per chromosome.

\section{PCR}

All PCR reactions were carried out in $7-\mu \mathrm{L}$ reaction mixtures containing $2 \mu \mathrm{L}$ of genomic DNA (10 ng/ $\mu \mathrm{L})$,
$0.7 \mu \mathrm{L}$ of $10 \times \mathrm{PCR}$ buffer, $0.12 \mu \mathrm{L}$ of dimethylsulfoxide, $0.2 \mu \mathrm{L}$ of each primer $(10 \mathrm{pmol} / \mu \mathrm{L}), 0.1 \mu \mathrm{L}$ of deoxynucleotide 5 '-triphosphates (5 $\mathrm{m} M$ each), and $0.05 \mu \mathrm{L}$ of Taq Polymerase (5 U/ $\mu \mathrm{L}$; Roche, Basel, Switzerland). To increase efficiency, primers were pooled into PCR multiplex groups. One primer of each pair was endlabeled with fluorescent IRD700 or IRD800 (Eurofins, MWG, Ebersberg, Germany). For amplification, PTC 200 thermal cyclers (MJ Research, Watertown, MA) and TProfessional Basic Thermocyclers (Biometra, Göttingen, Germany) and a general PCR program with variable annealing temperature were used. The reaction began with denaturing all samples at $94^{\circ} \mathrm{C}$ for 4 min, followed by 36 cycles comprising denaturation for $30 \mathrm{~s}$ at $94^{\circ} \mathrm{C}$, annealing for $50 \mathrm{~s}$ at annealing temperature $\left(52\right.$ to $\left.70^{\circ} \mathrm{C}\right)$, and extension for $50 \mathrm{~s}$ at $72^{\circ} \mathrm{C}$. The PCR was completed with a final cooling at $4^{\circ} \mathrm{C}$ for 10 min. For analysis of the marker genotypes, the PCR products were size-fractionated by gel electrophoresis on automated sequencers (LI-COR 4200 and 4300, LI-COR Biosciences, Lincoln, NE) by using 6\% polyacrylamide denaturing gels (RotiphoreseGel 40, Roth, Karlsruhe, Germany).

\section{Statistical Analysis}

Multipoint nonparametric linkage analyses based on haplotypes IBD for a half-sib design were used (Kruglyak et al., 1996; Kong and Cox, 1997). The statistical 


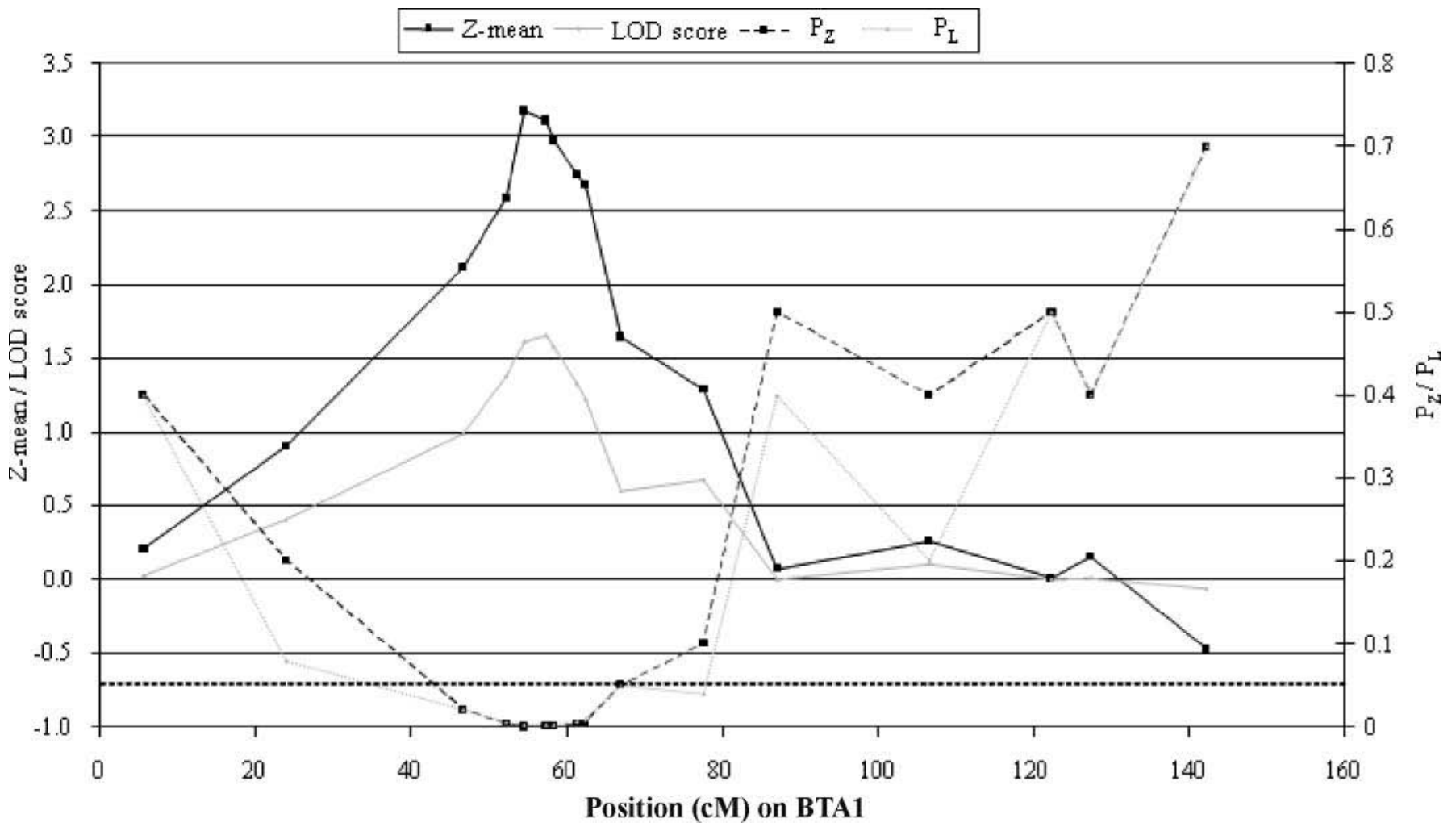

Figure 2. The Z-mean and LOD (logarithm of the odds) score profiles and their corresponding chromosome-wide error probabilities $\left(\mathrm{P}_{\mathrm{Z}}\right.$, $\mathrm{P}_{\mathrm{L}}$ ) for left-sided displacement of the abomasum in German Holstein cattle for bovine chromosome 1 (BTA1). Dots indicate marker positions. The dashed horizontal line indicates the threshold of chromosome-wide significance $\left(\mathrm{P}_{\mathrm{z}}=0.05\right)$.

analyses were performed by using MERLIN software, version 1.1.1 (Abecasis et al., 2002). The algorithm is based on a chromosome-wide multipoint nonparametric analysis of affected family members. Linkage between LDA and markers was estimated by the proportion of alleles shared IBD (Kong and Cox, 1997). Test statistics were the Z-mean and a logarithm of the odds (LOD) score according to Kong and Cox (1997). The maximum (minimum) achievable Z-mean was 49.12 (-3.25) for LDA and was thus high enough to reach a genome-wide significance level of $5 \%$. The corresponding maximum (minimum) value for LOD scores was $24.87(-0.48)$. In the case of no linkage, the Z-mean approaches the minimum achievable value for an equal distribution of alleles among affected relatives.

When linkage is present under the alternative hypothesis, the proportion of alleles IBD significantly deviates from the expected IBD proportions of the null hypothesis. Sires that are, at most, homozygous for a chromosome-wide haplotype are uninformative for the respective chromosome and thus cannot contribute to the test statistics. A falsely heterozygous sire could inflate the test statistics for linkage. Therefore, we carefully checked all sires heterozygous for the QTL-linked markers to ensure that the minor allele was present in at least 2 to 4 daughters. In almost all half-sib families, we could determine minor allele frequencies greater than 20\% (5 daughters on average). Multipoint analyses allowed the use of marker information from the whole chromosome, through linked informative markers, to detect double recombination events possibly caused by meiotic drive or natural or artificial selection for a paternal allele unrelated to LDA and to increase the power of linkage analysis.

We determined empirical chromosome-wide significance levels for Z-means and LOD scores by using MERLIN to create simulated marker genotypes under the null hypothesis of no linkage to observed phenotypes. In each simulation, we retained the original phenotypes and generated a new data set with random genotypes for each founder animal and each marker according to the allele frequencies given in the data analyzed. Pedigree relationships were used to assign marker genotypes to the progeny, assuming Mendelian segregation and recombination fractions as given in the bovine linkage map used in this study. The empirical distribution for the 5\% error probability was obtained after 1,000 replicates. A significant chromosome-wide 


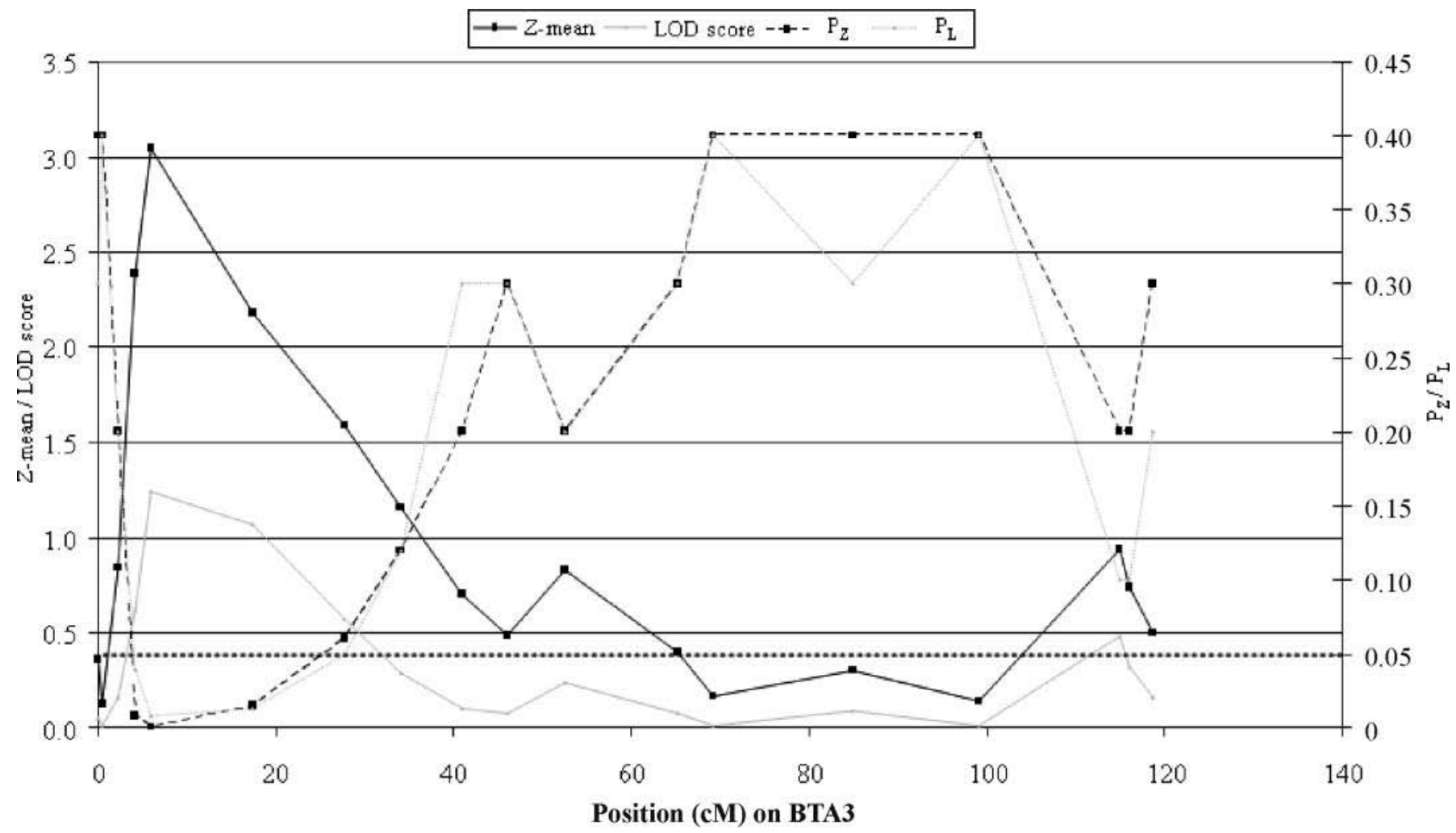

Figure 3. The Z-mean and LOD (logarithm of the odds) score profiles and their corresponding chromosome-wide error probabilities $\left(\mathrm{P}_{\mathrm{Z}}\right.$, $\mathrm{P}_{\mathrm{L}}$ ) for left-sided displacement of the abomasum in German Holstein cattle for bovine chromosome 3 (BTA3). Dots indicate marker positions. The dashed horizontal line indicates the threshold of chromosome-wide significance $\left(\mathrm{P}_{\mathrm{z}}=0.05\right)$.

cosegregation of marker alleles among affected family members with the phenotypic expression of LDA was assumed for the empirically determined significance levels below $5 \%$. Genome-wide significance levels were obtained for the chromosome-wide error probabilities of Z-means and LOD scores ( $\left.\mathrm{P}_{\text {chromosome-wide }}\right)$ by applying a Bonferroni correction (de Koning et al., 1999): $\mathrm{P}_{\text {genome-wide }}=1-\left(1-\mathrm{P}_{\text {chromosome-wide }}\right)^{1 / \mathrm{r}}$, where $\mathrm{r}$ is the length of the respective bovine chromosome in $\mathrm{cM}$ divided by the total bovine genome length of $3,160 \mathrm{cM}$ (Ihara et al., 2004). Bonferroni's procedure strictly controls the overall type I error rate but is known to be conservative when many null hypotheses are tested and these are correlated. Because chromosomes are inherited independently, correlations among null hypotheses are not expected; therefore, genome-wide error probabilities should not be too conservative.

\section{RESULTS}

\section{Quality of the Marker Set Used}

The 306 microsatellite markers used for the wholegenome scan and the fine-mapping had a mean of 7.6 alleles, ranging from 2 to 18 . The average polymorphism information content in our data was $56.7 \%$, and the mean heterozygosity was $61.6 \%$. For the genome scan, 221 microsatellite markers with an average marker distance of $13.7 \mathrm{cM}$ were used. The number of markers per chromosome ranged from 4 on Bos taurus autosome (BTA) 27 and 28, to 10 on BTA5. Marker density was greatest on BTA29, with an average distance of 9.96 $\mathrm{cM}$, and was lowest on BTA27, with an average distance of $17.8 \mathrm{cM}$. After including 85 additional markers on 14 chromosomes, the average marker distance was $7.9 \mathrm{cM}$ on the respective chromosomes.

\section{Whole-Genome Scan and Fine-Mapping}

In the whole-genome scan, we detected putative genomic regions with linkage to LDA on 14 bovine chromosomes (BTA1, 3, 5, 6, 10, 12, 15, 16, 17, 19, 21, 23, 24 , and 26). Therefore, all chromosomes showing putative linkage with LDA were fine-mapped by using 85 additional microsatellite markers. Five QTL with chromosome-wide error probabilities of Z-means and LOD scores below 0.05 on 5 bovine chromosomes (BTA1, 3, 21,23 , and 24) were confirmed by 2 to 8 microsatellites 


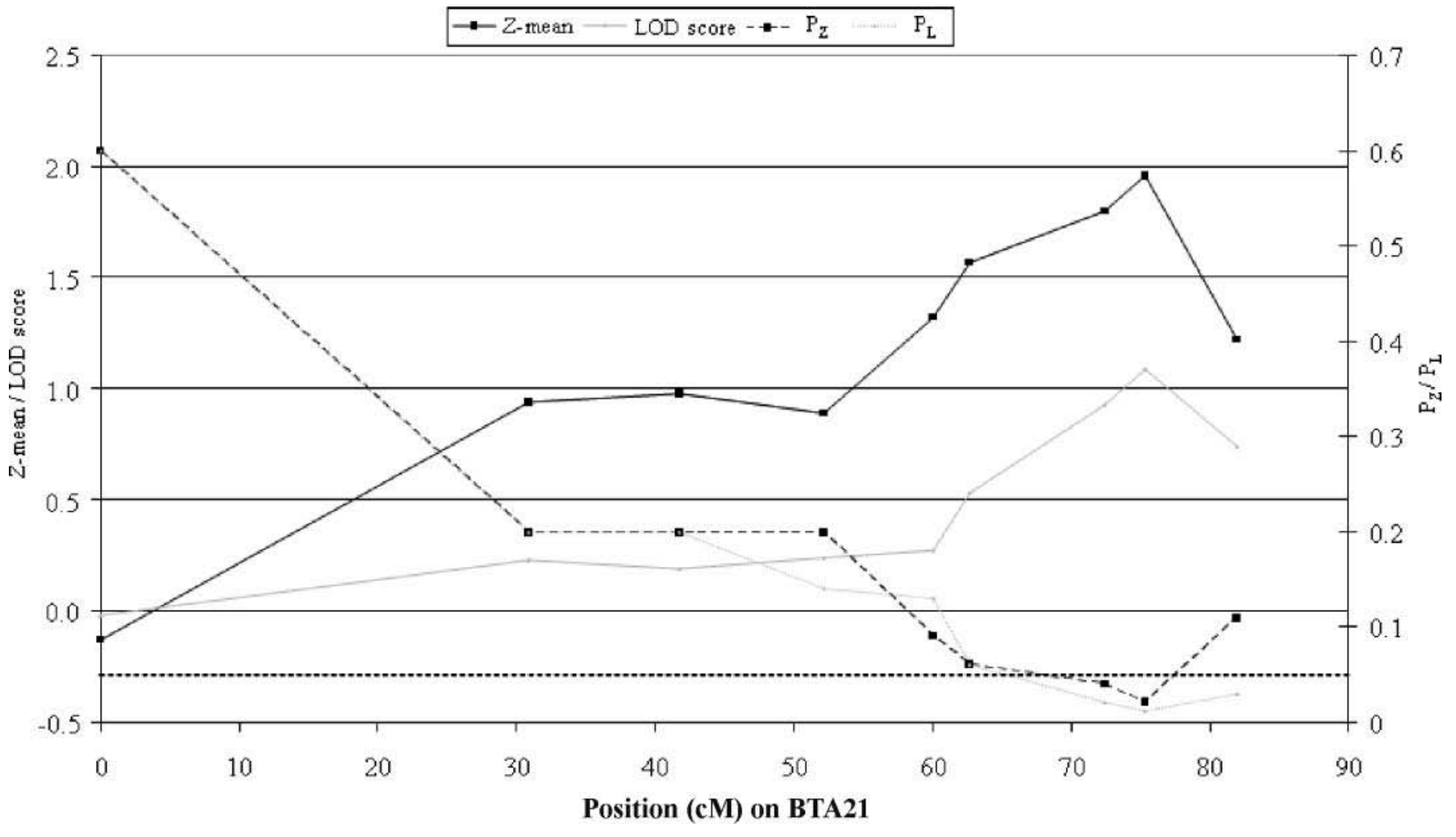

Figure 4. The Z-mean and LOD (logarithm of the odds) score profiles and their corresponding chromosome-wide error probabilities $\left(\mathrm{P}_{\mathrm{Z}}\right.$, $\mathrm{P}_{\mathrm{L}}$ ) for left-sided displacement of the abomasum in German Holstein cattle for bovine chromosome 21 (BTA21). Dots indicate marker positions. The dashed horizontal line indicates the threshold of chromosome-wide significance $\left(\mathrm{P}_{\mathrm{z}}=0.05\right)$.

per QTL (Table 1). Genome-wide significance for the Z-means was found on BTA1 for 3 microsatellites $(54.6$ to $58.3 \mathrm{cM})$ and on BTA3 for 1 microsatellite $(5.9 \mathrm{cM})$.

The region of linkage on BTA1 spanned from 23.9 to $77.7 \mathrm{cM}$ when analyzing all families (Figure 2). The linked region on BTA3 extended between 2.2 and 27.7 cM (Figure 3). For BTA21, the QTL was located between 62.7 and $82.0 \mathrm{cM}$ (Figure 4). On BTA23, the QTL extended between the proximal end of the chromosome $(0 \mathrm{cM})$ and $9.6 \mathrm{cM}$ (Figure 5), and on BTA24, the QTL ranged from $68.5 \mathrm{cM}$ to the distal end of the chromosome (78.1 cM; Figure 6).

After this conjoined analysis, we performed separate analyses for the 5 grandsire families. We detected further regions with chromosome-wide significant linkage to LDA, which were present in only 1 or 2 grandsire families. These QTL were located centrally on BTA15 in 2 grandsire families and distally on BTA5, proximally on BTA6, distally on BTA10, distally on BTA12, centrally on BTA16, centrally on BTA17, distally on BTA19, distally on BTA23, and distally on BTA26, each in only 1 grandsire family. The region on BTA26 showed genome-wide significance. The positions of these QTL on the bovine genome are given in Table 2.

\section{DISCUSSION}

We detected 2 genome-wide and 3 chromosome-wide significant QTL for LDA on 5 bovine chromosomes. This is the first report of a whole-genome scan and QTL identified for LDA in dairy cattle. No previously reported genome scans for health traits in dairy cattle included this disease because of missing health records in daughters. Thus, we used an affected half-sib design and ascertainment of cases through 2 clinics for cattle at veterinary universities. We were able to collect large half-sib families and even larger grandsire families with dairy cows being affected by LDA, as well as control cows producing more than 7 lactations without being affected by LDA. The reliability of our phenotypic data is high because of the diagnosis of LDA confirmed by veterinary experts and by a report on the surgical intervention for each cow. Heterozygosity of the sires at the QTL-linked markers was ensured through a relatively high frequency of daughters showing the minor alleles of the heterozygous sires. We used a chromosome-wide significance threshold of $P=0.05$ over 30 bovine chromosomes to discriminate among putative and significant QTL. Because all the 5 QTL 


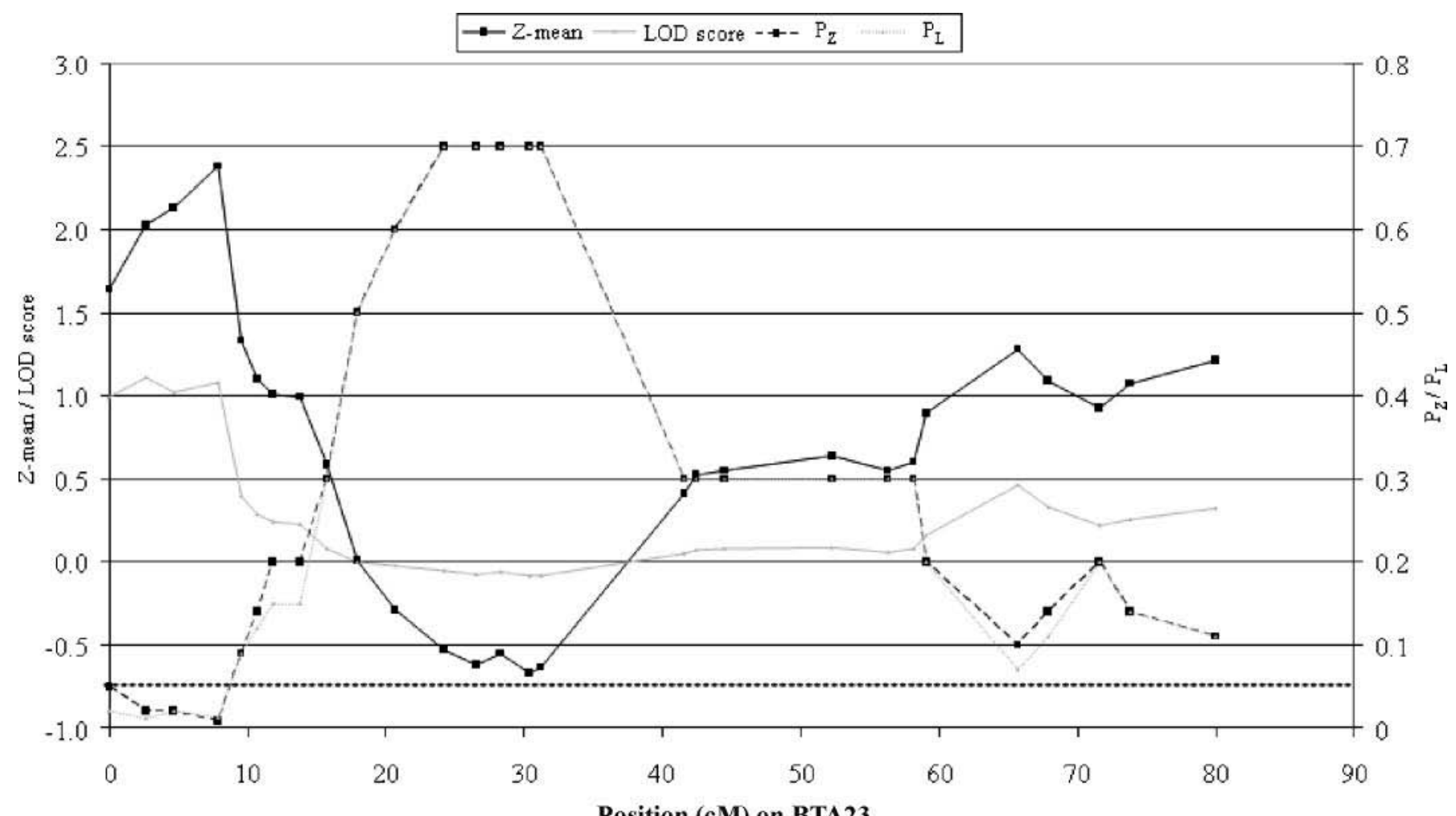

Figure 5. The Z-mean and LOD (logarithm of the odds) score profiles and their corresponding chromosome-wide error probabilities $\left(\mathrm{P}_{Z}\right.$, $\mathrm{P}_{\mathrm{L}}$ ) for left-sided displacement of the abomasum in German Holstein cattle for bovine chromosome 23 (BTA23). Dots indicate marker positions. The dashed horizontal line indicates the threshold of chromosome-wide significance $\left(\mathrm{P}_{\mathrm{z}}=0.05\right)$.

showed error probabilities equal to or below 0.01 for at least one marker, a chromosome-wide significance might be obtained only for 0.3 chromosomes purely by chance. Thus, the power of our experiment seemed to be sufficient to detect significant QTL.

The results of linkage analyses may be biased if the probability of receiving either paternal allele is unequal. This can be caused by meiotic drive or natural or artificial selection for one of the paternal alleles for reasons unrelated to the trait of interest. Meiotic drive results in non-Mendelian segregation of alleles to offspring (Lyttle, 1993). Two-point linkage analyses are much more sensitive to these biases compared with multipoint analyses. An overrepresentation of a specific allele in the chromosomal haplotypes of many affected half-sibs would cause double recombination in a large proportion of these animals. Because we could not observe double recombination events in the QTL for LDA, segregation distortion caused by meitotic drive or unexpected selection forces could be ruled out. In addition, the unaffected sibs in the analysis did not reveal segregation distortion, even if the sample size of unaffected cows was small. Furthermore, the 5 chromosome-wide significant QTL for LDA were also significant for all or almost all the 14 half-sib families in analyses separately for the single families. Thus, natural or artificial selection for one of the paternal alleles or haplotypes in so many AI sires would be unlikely to go unnoticed. Therefore, we can exclude meiotic drive, natural selection, and artificial selection unrelated to LDA as reasons for significant linkage with LDA in our data.

The prevalence of LDA was reported to be genetically correlated with milk yield $\left(\mathrm{r}_{\mathrm{g}}=0.683 \pm 0.227\right)$, milk fat yield $\left(r_{\mathrm{g}}=0.595 \pm 0.297\right)$, and milk protein yield $\left(r_{\mathrm{g}}=\right.$ $0.653 \pm 0.25$ ) (Ricken et al., 2004). Therefore, it can be assumed that some QTL for milk performance traits may overlap with QTL for LDA, particularly in Holstein cows. The QTL for milk yield, milk fat yield, and milk protein yield sharing a genomic region with QTL for LDA were identified on BTA1, 3, 21, and 23. These QTL for milk performance traits were already based on the linkage map of Ihara et al. (2004) or were converted to this map, which was also used in this study.

The QTL for LDA on BTA1 overlaps a QTL region for several milk performance traits, with QTL for milk yield extending from 5.1 to $51.0 \mathrm{cM}$ (Georges et al., 1995) and extending from 67.7 to $69.8 \mathrm{cM}$ (Nadesal- 


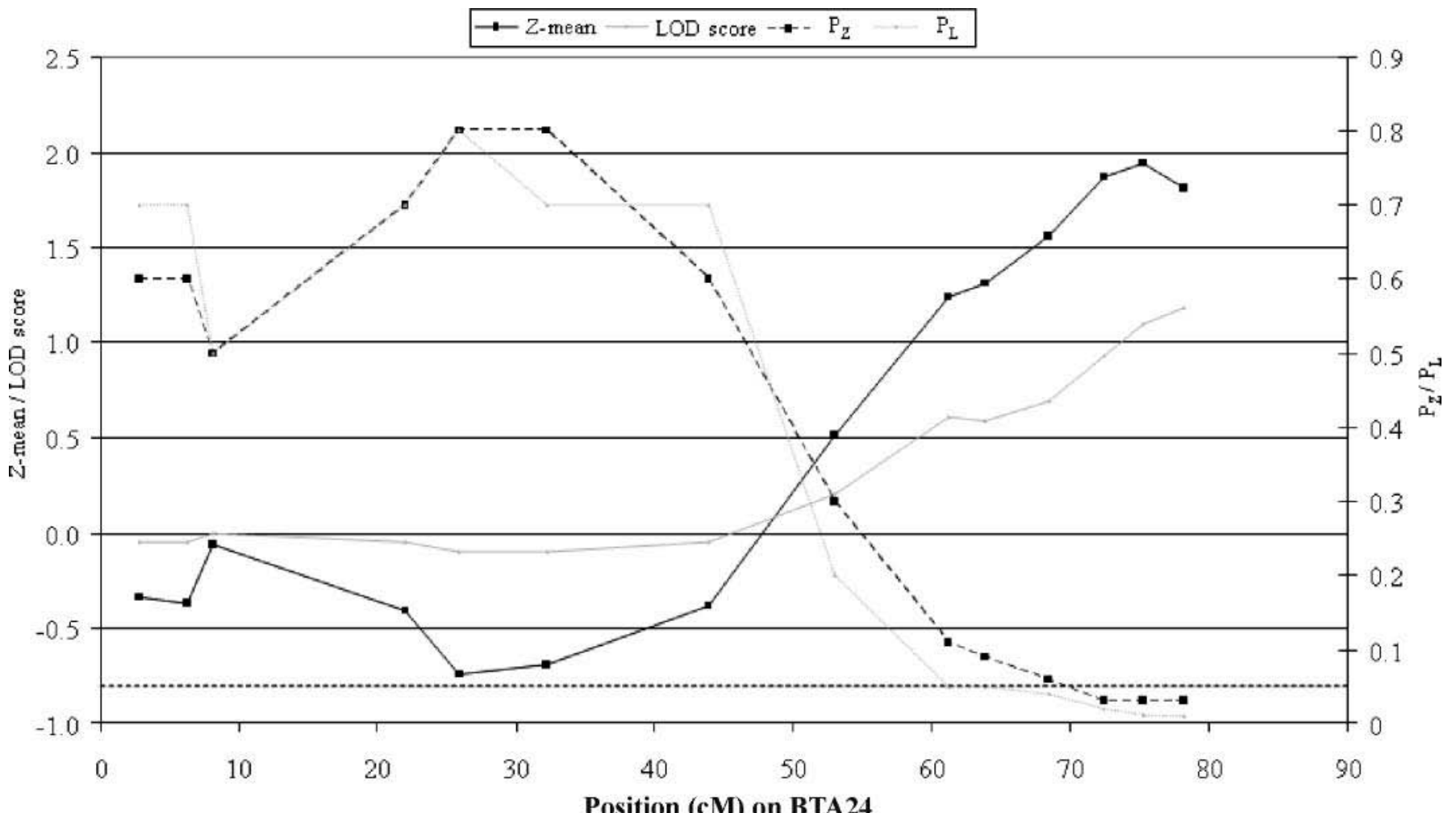

Figure 6. The Z-mean and LOD (logarithm of the odds) score profiles and their corresponding chromosome-wide error probabilities $\left(\mathrm{P}_{\mathrm{Z}}\right.$, $\mathrm{P}_{\mathrm{L}}$ ) for left-sided displacement of the abomasum in German Holstein cattle for bovine chromosome 24 (BTA24). Dots indicate marker positions. The dashed horizontal line indicates the threshold of chromosome-wide significance $\left(\mathrm{P}_{\mathrm{z}}=0.05\right)$.

ingam et al., 2001) mapped to the genomic region on BTA1, where the LDA-QTL was located. The QTL for milk protein yield on BTA1 were located between 5.1 and $51.0 \mathrm{cM}$ (Georges et al., 1995) and between 45.3 and $60.3 \mathrm{cM}$ (Nadesalingam et al., 2001). These milk protein QTL were in the same genomic region as the QTL for LDA. However, because milk protein yield is a function of milk yield and protein content, the QTL for milk protein yield might be largely based on genes affecting milk yield. Further, QTL for milk fat yield and fat percentage were mapped between 5.1 and $51.0 \mathrm{cM}$ (Georges et al., 1995) and therefore located in the same region as the QTL for LDA.

On BTA3, QTL for milk fat yield between 0.0 and $27.4 \mathrm{cM}$ in Norwegian dairy cattle (Olsen et al., 2002) and for milk protein yield in US Holsteins between 0.0 and $46.0 \mathrm{cM}$ (Zhang et al., 1998) were found in the same region as the QTL for LDA. A QTL for milk protein percentage and milk fat yield was mapped on BTA3 between 22.6 and $27.4 \mathrm{cM}$ in US Holsteins (Ashwell et al., 2004) and thus overlaps with the QTL for LDA.

On BTA21, QTL for milk fat percentage at 62.7 cM (Rodriguez-Zas et al., 2002) and for milk protein percentage at $65.9 \mathrm{cM}$ (Rodriguez-Zas et al., 2002) are located within the QTL for LDA on this chromosome. A QTL for milk yield on BTA23 between 11.8 and $20.7 \mathrm{cM}$ (Viitala et al., 2003) is in close vicinity of the QTL for LDA. Thus, the joint distribution of QTL for milk performance traits and LDA suggests that a cosegregation of loci influencing both trait complexes may be possible, even if not all the milk performance QTL overlapping with QTL for LDA may segregate in GH cows.

Possible candidate genes for LDA might be involved in the development of the intrinsic nervous system, the vegetative nervous system, and the function of neurotransmitters. Furthermore, a high serum concentration of insulin was shown to be involved in the clinical manifestation of LDA (Pravettoni et al., 2004). Therefore, greater insulin production as well as a low production level of the antagonizing hormone glucagon might predispose cows to LDA. Genes involved in the insulin-glucagon metabolism and its regulation could be possible candidates. One of those genes is INSRR (insulin receptor-related receptor), which is located at 15.7 $\mathrm{Mb}$ (B. taurus build 4.0) and is thus a positional candidate gene, because the QTL for LDA on BTA3 
Table 2. Quantitative trait loci for left-sided displacement of the abomasum in German Holstein cattle with chromosome-wide significance in 1 or 2 grandsire families ${ }^{1}$

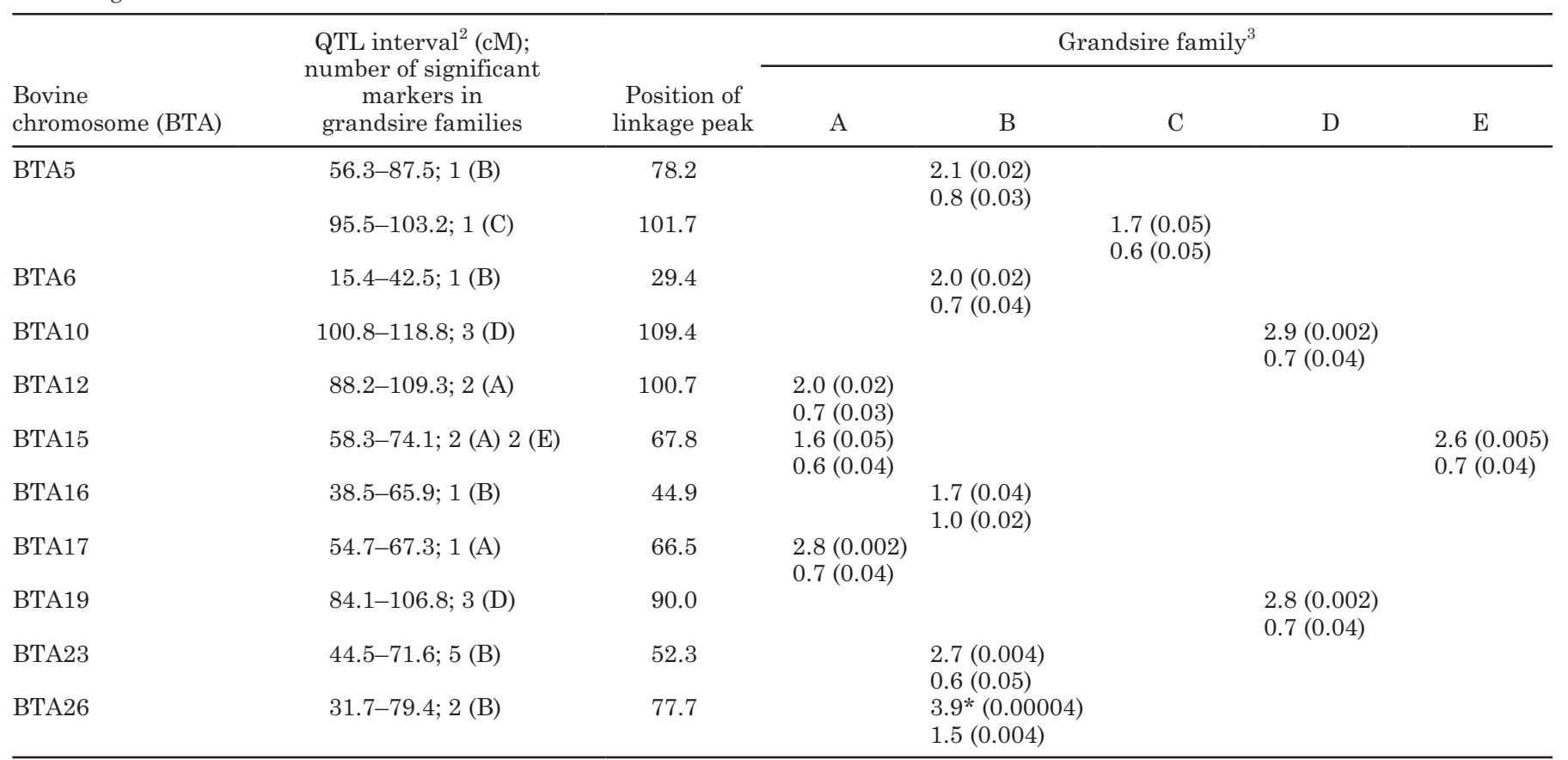

${ }^{1}$ For each grandsire family, the QTL interval delimited by chromosome-wide significant markers (cM), the number of chromosome-wide significant markers, and the maximum Z-means and LOD (logarithm of the odds) scores with their chromosome-wide error probabilities ( $\mathrm{P}_{Z}, \mathrm{P}_{\mathrm{L}}$ ) are shown. Because the QTL intervals on bovine chromosome 5 (BTA5) do not overlap, they are presented separately.

${ }^{2}$ The QTL interval was determined by the positions (cM) of the two markers directly flanking those most distantly located markers at the QTL showing chromosome-wide significant linkage $(P<0.05)$ for Z-means and LOD scores.

${ }^{3}$ The Z-mean $\left(\mathrm{P}_{\mathrm{Z}}\right)$ is shown above, and the LOD score $\left(\mathrm{P}_{\mathrm{L}}\right)$ is shown below.

*Genome-wide error probability $(P<0.01)$.

extends between 1.8 and $17.1 \mathrm{Mb}$ (DIK2421, DIK2101; BLAST search in B. taurus build 4.0). A further possible candidate gene is the dopamine receptor gene (DRD3) located on BTA1, which plays a role in the diabetic gastric paresis in the rat (Qin et al., 2003). The gene DRD3 is located at $52.8 \mathrm{Mb}$ on BTA1 and is thus located within the QTL for LDA between the markers BMS711 at $16.8 \mathrm{Mb}$ (NCBI B. taurus build 4.0) and BM6506 at $72.0 \mathrm{Mb}$ (NCBI B. taurus build 4.0).

Genomic regions on 10 different chromosomes reached chromosome-wide-and in one case even genome-wide-significance thresholds for linkage with LDA in the separate grandsire-family analysis including 1,4 , or 7 sire families, respectively. However, these regions were not significantly linked in the acrossfamily analysis. It may be likely that only some of the grandsires and sires segregate for these regions and that the effects of the QTL for LDA in these regions are smaller than those of the chromosome-wide QTL identified in the across-family analyses. Results showing significance only within grandsire or sire families should not be neglected, even if more markers, grand- daughters, and daughters in these genomic regions need to be studied for confirmation.

This study is a first step toward molecular genetic characterization of QTL for LDA. Development of single nucleotide polymorphisms will be done in fine-mapping studies, and markers in population-wide linkage disequilibrium with LDA may then become available for marker-assisted selection programs.

\section{CONCLUSIONS}

This is the first study to identify QTL for LDA in dairy cattle by using 306 microsatellite markers and 360 animals. These results provide evidence of 2 genome-wide significant QTL for LDA on BTA1 at 54.6 to $58.3 \mathrm{cM}(M N B 152, D I K 4483)$ and BTA3 at $5.9 \mathrm{cM}$ (DIK4922), respectively, and an additional 3 chromosome-wide significant QTL for LDA on BTA21 at 62.7 to $82.0 \mathrm{cM}$ (TGLA122, BB6), BTA23 at 0.0 to $9.6 \mathrm{cM}$ (DIK5319, DIK4865), and BTA24 at 68.5 to $78.1 \mathrm{cM}$ (DIK2706, DIK4971). Further fine-mapping of these 
QTL is necessary to unravel the genes contributing to the development of LDA in Holstein dairy cows.

\section{ACKNOWLEDGMENTS}

This study was supported by a grant from the German Research Council (DFG, Bonn, Germany; MO1691/1-1).

\section{REFERENCES}

Abecasis, G. R., S. S. Cherny, W. O. Cookson, and L. R. Cardon. 2002. Merlin-rapid analysis of dense genetic maps using sparse gene flow trees. Nat. Genet. 30:97-101.

Ashwell, M. S., D. W. Heyen, T. S. Sonstegard, C. P. Van Tassell, Y. Da, P. M. Van Raden, M. Ron, J. I. Weller, and H. A. Lewin. 2004 Detection of quantitative trait loci affecting milk production, health, and reproductive traits in Holstein cattle. J. Dairy Sci. 87:468-475.

Constable, P. D., G. Y. Miller, G. F. Hoffsis, B. L. Hull, and D. M. Rings. 1992. Risk factors for abomasal volvulus and left abomasal displacement in cattle. Am. J. Vet. Res. 53:1184-1192.

de Koning, D. J., L. L. Janss, A. P. Rattink, P. A. van Oers, B. J. de Vries, M. A. Groenen, J. J. van der Poel, P. N. de Groot, E W. Brascamp, and J. A. van Arendonk. 1999. Detection of quantitative trait loci for backfat thickness and intramuscular fat content in pigs (Sus scrofa). Genetics 152:1679-1690.

Detilleux, J. C., Y. T. Gröhn, S. W. Eicker, and R. L. Quaas. 1997. Effects of left displaced abomasum on test day milk yields of Holstein cows. J. Dairy Sci. 80:121-126.

Geishauser, T., D. Reiche, and M. Schemann. 1998. In vitro motility disorders associated with left-sided displaced abomasum in dairy cows. Neurogastroenterol. Motil. 10:395-401.

Georges, M., D. Nielsen, M. Mackinnon, A. Mishra, R. Okimoto, A. T. Pasquino, L. S. Sargeant, A. Sorensen, M. R. Steele, X. Zhao, J. E. Womack, and I. Hoeschele. 1995. Mapping quantitative trait loci controlling milk production in dairy cattle by exploiting progeny testing. Genetics 139:907-920.

Grymer, J., P. Willeberg, and M. Hesselholt. 1982. Milk production and left displaced abomasum cause and effect relationships. Nord. Vet. Med. 34:412-415.

Hamann, H., V. Wolf, H. Scholz, and O. Distl. 2004. Relationships between lactational incidence of displaced abomasum and milk production traits in German Holstein cows. J. Vet. Med. A 51:203-208.

Ihara, N., A. Takasuga, K. Mizoshita, H. Takeda, M. Sugimoto, Y. Mizoguchi, T. Hirano, T. Itoh, T. Watanabe, K. M. Reed, W. M. Snelling, S. M. Kappes, C. W. Beattie, G. L. Bennett, and Y. Sugimoto. 2004. A comprehensive genetic map of the cattle genome based on 3802 microsatellites. Genome Res. 14:19871998.

Jubb, T. F., J. Malmo, G. M. Davis, and A. S. Vawser. 1991. Left-side displacement of the abomasum in dairy cows at pasture. Aust. Vet. J. 68:140-142.

Kong, A., and N. J. Cox. 1997. Allele-sharing models: LOD scores and accurate linkage tests. Am. J. Hum. Genet. 61:1179-1188.
Kruglyak, L., M. J. Daly, M. P. Reeve-Daly, and E. S. Lander. 1996 Parametric and nonparametric linkage analysis: A unified multipoint approach. Am. J. Hum. Genet. 58:1347-1363.

Lyttle, T. W. 1993. Cheaters sometimes prosper: Distortion of mendelian segregation by meiotic drive. Trends Genet. 9:205210.

Martin, S. W., K. L. Kirby, and R. A. Curtis. 1978. Left abomasal displacement in dairy cows: Its relationship to production. Can. Vet. J. 19:250-253.

Nadesalingam, J., Y. Plante, and J. P. Gibson. 2001. Detection of QTL for milk production on chromosomes 1 and 6 of Holstein cattle. Mamm. Genome 12:27-31.

Olsen, H. G., L. Gomez-Raya, D. I. Vage, I. Olsaker, H. Klungland, M. Svendsen, T. Adnoy, A. Sabry, G. Klemetsdal, N. Schulman, W. Kramer, G. Thaller, K. Ronningen, and S. Lien. 2002. A genome scan for quantitative trait loci affecting milk production in Norwegian dairy cattle. J. Dairy Sci. 85:3124-3130.

Pravettoni, D., K. Doll, M. Hummel, E. Cavallone, M. Re, and A. G. Belloli. 2004. Insulin resistance and abomasal motility disorders in cows detected by use of abomasoduodenal electromyography after surgical correction of left left-sided displaced abomasum. Am. J. Vet. Res. 65:1319-1324.

Qin, X. Y., Z. G. Wang, J. Fei, F. L. Liu, D. F. Ciu, and S. L. Chen. 2003. Involvement of Dopamine D3 and Neuropeptide Y Y5 receptors in diabetic gastroparetic rats without response to erythromycin. Acta Biochim. Biophys. Sin. (Shanghai) 35:811-815.

Ricken, M., H. Hamann, H. Scholz, and O. Distl. 2004. [Genetic analysis of the prevalence for abomasal displacement and its relation to milk performance traits in German Holstein cows]. Dtsch. Tierärztl. Wochenschr. 111:366-370.

Ricken, M., H. Hamann, H. Scholz, and O. Distl. 2005. [Analysis of survival of German Holstein cows after developing an abomasal displacement]. Dtsch. Tierärztl. Wochenschr. 112:55-65.

Rodriguez-Zas, S. L., B. R. Southey, D. W. Heyen, and H. A. Lewin 2002. Interval and composite interval mapping of somatic cell score, yield, and components of milk in dairy cattle. J. Dairy Sci. 85:3081-3091.

Rohrbach, B. W., A. L. Cannedy, K. Freeman, and B. D. Slenning. 1999. Risk factors for abomasal displacement in dairy cows. J. Am. Vet. Med. Assoc. 214:1660-1663.

Sickinger, M. 2007. [Neuropeptide yield of the bovine abomasal wall against breed and displacement condition]. Thesis. JustusLiebig-University Gießen, Germany.

Viitala, S. M., N. F. Schulman, D. J. de Koning, K. Elo, R. Kinos, A. Virta, J. Virta, A. Mäki-Tanila, and J. H. Vilkki. 2003. Quantitative trait loci affecting milk production traits in Finnish Ayrshire dairy cattle. J. Dairy Sci. 86:1828-1836.

Wolf, V., H. Hamann, H. Scholz, and O. Distl. 2001a. [Influences on the development of abomasal displacement in German Holstein cows]. Dtsch. Tierärztl. Wochenschr. 108:403-408.

Wolf, V., H. Hamann, H. Scholz, and O. Distl. 2001b. [Systematic influences on the development of abomasal displacements in German Holstein cows]. Züchtungskunde 73:257-265.

Zhang, Q., D. Boichard, I. Hoeschele, C. Ernst, A. Eggen, B. Murkve, M. Pfister-Genskow, L. A. Witte, F. E. Grignola, P. Uimari, G. Thaller, and M. D. Bishop. 1998. Mapping quantitative trait loci for milk production and health of dairy cattle in a large outbred pedigree. Genetics 149:1959-1973. 